\title{
Una aproximación a \\ los deloates solore el \\ conocimiento histórico: \\ del siglo XIX al XXI
}

\section{Fabrizio Lorusso ${ }^{1}$ \\ fabriziolorusso@yahoo.it \\ An approach to the debates on the \\ historical knowledge: from the 19th to \\ 21st centuries}

Resumen

El artículo es un acercamiento a los debates sobre el conocimiento histórico de los siglos XIX al XXI. La primera parte describe los cambios en la historiografía en el paso del paradigma rankeano del siglo XIX al siglo XX, con la Escuela de los Annales y enfoques estructuralistas, marxistas o cuantitativos. La segunda considera las evoluciones en el siglo $\mathrm{XX}$, incluyendo el giro lingüístico. La tercera revisa el debate entre los viejos paradigmas, los últimos Annales y las distintas o "nuevas historias", tras el llamado giro cultural y el surgimiento de la Historia Global y la Historia del Tiempo Presente. Se describe cómo la metodología de historia oral ha ganado legitimación y es utilizada cada vez más por investigadores.

Palabras clave: debate historiográfico, giro cultural, paradigma rankeano, Annales, nueva historia.

\section{Abstract}

This paper is an approach to the debates on the historical knowledge from the 19th century, to the 21st centuries. The first part describes the changes in historiography the development of the rankeano paradigm from the 19 th to the 20th century, with the Annales school and the structuralist views, Marxist and quantitative approaches. The second considers León, México.

Blvd. Jorge Vértiz Campero 1640, Col. Cañada de Alfaro, C.P. 37238, León, Guanajuato,

México.

Departamento de Ciencias Sociales y Humanidades, Universidad Iberoamericana de

the evolutions through the 20th century, including the linguistic change. The third reviews the debate between the latest $A n$ nales and the different or new "histories", after the so-called cultural turn and the emersion of Global History and History of the Present. It describes how Oral History methodology has gained legitimation and is increasingly used by researchers.

Key word.s: historiographic debate, cultural turn, rankean paradigm, Annales, new history. ${ }^{1}$

Letras Históricas / Número 17 / Otoño 2017-invierno 2018 / México / pp. 209-235 / ISSN: 2448-8372 


\section{El paradigma rankeano y}

\section{la historia centrada en lo nacional}

Durante todo el siglo XIX y principios del XX, la historiografía se centró principalmente en lo nacional, entendido no tanto como atención hacia el país de origen de los estudiosos, sino más bien como investigación del proceso de formación del Estado para mantener y reelaborar la memoria del pasado nacional que desemboca de manera cuasi-determinista en la forma del Estado-nación occidental y westfaliano. Con respecto a Francia, Italia y Alemania, la historiografía de Inglaterra centró su foco de atención más en los procesos de la Revolución Industrial y en su construcción imperial; sin embargo, también allí, a mediados del siglo XVIII, se publicaron obras como la monumental History of England de David Hume, escrita entre 1754 y 1761, que empieza a romper con las visiones trascendentes y deterministas de la historia para rescatar una visión secularista y natural de los acontecimientos (Mossner, 1980, pp. 304-309).

En el siglo XIX se dejó caer gradualmente el proyecto de "historia universal" iluminista, propugnado por Voltaire o la escuela de Göttingen, con Johann Christoph Gatterer y August Ludwig von Schlözer, a favor de una historia básicamente eurocéntrica y nacional o, en el mejor de los casos, de un grupo de naciones o países de un área geográfica definida, como en el trabajo de Leopold von Ranke (1795-1886), el mayor representante de la historiografía alemana de ese periodo, y su Weltgeschichte ("historia mundial"), la cual está más bien ligada a las naciones romano-germánicas. Europa se entendía como centro, superior a las sociedades extraeuropeas y, dentro del viejo continente, asimismo, podía incluso justificarse la primacía o mayor "universalidad" e influencia de una nación sobre las otras, ya sea en términos culturales o políticos (Guizot, 1851). Nacionalismo y romanticismo acompañan la historia como legitimaciones del Estado nacional y la emersión de una historia "con fines propios y dimensión universal", una "historia científica", se da en el contexto del desarrollo de la burguesía, clase en ascenso y en busca de claves para la interpretación del mundo en los siglos XVIII y XIX (Florescano, 2012, p. 81).

Sin embargo, ya hacia la segunda mitad de la centuria se perfiló una orientación distinta, desligada del pasado nacional y más atenta a la estructura de clases de la sociedad europea: si bien la historiografía propiamente marxista tuvo sus desarrollos más destacados en el siglo XX, tanto en Europa como en Latinoamérica, Karl Marx fue quien ofreció una panorámica general del paso de la sociedad feudal a la industrial dentro de la historia moderna europea, y de la estructura, la evolución y los 
mecanismos de las clases sociales que la caracterizaban. Se iba creando entonces un interés por las revoluciones, la lucha de clases, los vuelcos sociopolíticos y la economía capitalista, más allá de los "grandes personajes" y los acontecimientos políticos. La dimensión económica y el desarrollo comenzaron a introducirse en el discurso histórico. Además, el mismo surgimiento de los Estados Unidos de Norteamérica, con su mezcla de confesiones religiosas, migrantes e instituciones nuevas, salió del "esquema nacional" clásico, como lo relató Alexis de Tocqueville en sus dos tomos de De la démocratie en Amérique (1835 y 1840).

A finales del siglo XIX los fenómenos del pasado, así como el "paradigma nacional" dominante, ya no eran campos exclusivos para la historia, sino también para otras disciplinas nacientes como la antropología, la ciencia económica y la sociología, que podían poner en entredicho su modelo interpretativo dominante o "rankeano". Asimismo, sin romper con este paradigma, despuntan orientaciones positivistas o "cientificistas" en la historiografía entre finales del XIX e inicios del XX, y, en América Latina, esto se da en la fase de construcción y legitimación del estado liberal-oligárquico, justificado a partir del lema "orden y progreso" que campea en la bandera brasileña y en las ideas de las elites (Sierra, 1985; Ingenieros, 1980). De todas formas, tampoco las reacciones historicistas y relativistas, con Benedetto Croce y R. G. Collingwod, entre otros, modifican sustancialmente el quehacer histórico convencional que se había consolidado en las décadas precedentes (Croce, 1952; Gooch, 1942).

En su dimensión social y cultural, el concepto de tiempo puede ser entendido como respuesta de una sociedad, en un determinado momento histórico, a la pregunta: "¿Cuándo hacer esta cosa?" En su dialéctica con las disciplinas históricas, el sociólogo Norbert Elias definió el tiempo como "una forma de relación y no, como lo creyó Newton, un flujo objetivo, parte de la Creación, como los ríos y las montañas" (Elias, 1997, p. 54). En este sentido, en un continuum temporal, "las preguntas sobre el cuándo se enfocan a establecer, dentro de un flujo continuo de acontecimientos, los sucesos, y a fijar hitos que señalan los comienzos y finales relativos dentro del flujo, a destacar un lapso de tiempo de otro, o a comparar ambos respecto de su longitud, que nosotros llamamos duración" (Elias, 1997, p. 83).

Según las palabras de Croce, citadas por Jean-Noël Luc (1981, p. 70), "la historia no se construye jamás a base de narraciones, sino siempre con base en documentos o narraciones reducidas a escala de documentos y tratadas como tales", lo cual, sin embargo, no significa que el documento sea todo lo que hace falta para analizar el pasado, como lo destacó Lucien Febvre con tono crítico y sarcástico: 
Voy a decíroslo... Recoged los hechos. Para ello, id a los archivos, esos graneros de hechos. Allí no hay más que agacharse para recolectar. Llenad bien los cestos. Desempolvadlos bien. Ponedlos encima de vuestra mesa. Haced lo que hacen los niños cuando se entretienen con cubos y trabajan para reconstruir la bella figura que nosotros, a propósito, les hemos desordenado... Se acabó el trabajo, la Historia está hecha" (Febvre, 1975, p. 180).

El modelo tradicional del siglo XIX se mantuvo fuerte en Alemania, con el historicismo filosófico como piedra angular, pero fue efectivamente reformado en Francia, donde el historiador pasó a tener la tarea de favorecer una síntesis entre métodos y hallazgos de distintas ciencias sociales con Henri Berr y, casi medio siglo después, con el mismo Braudel, ya que el análisis de fenómenos coyunturales y de larga duración necesitaba de las contribuciones de la demografía, la etnología, la geografía humana y económica, la lingüística y la antropología, con el fin de que se integraran en una "historia total": por lo tanto, el Mediterráneo de Braudel, con su multiplicidad de territorios, culturas, centros y estados, es una región económica y cultural, ya no una unidad política de tipo nacional, $\mathrm{y}$, asimismo, es portador de enfoques comparativos, marginalizados por Von Ranke pero valorados por el diálogo conceptual y disciplinar entre la historia y la sociología, como lo muestra por ejemplo el discurso de Max Weber (1984) sobre la ética económica comparada de las religiones universales en clave histórica.

Pese a las críticas y a la evolución de las didácticas, el uso serial, mecánico y acrítico de los documentos encadenados uno tras otro, así como los hechos que describen, como preveía la historiografía de corte positivista en el siglo XIX que se aplicó en la elaboración de las historias nacionales también en América Latina, todavía fue importante en la segunda mitad del siglo pasado, inclusive en la enseñanza de la historia, así como en su escritura, lo cual llega a cristalizar la correspondencia entre narraciones y hechos reales, entre la palabra del docente o del historiador y la verdad histórica (Audiger, 2001, p. 133).

\section{La historiografía en el siglo xx}

El "Novecientos" de la historiografía no coincide necesariamente con el siglo XX, en el sentido de que empieza a lo menos unas tres décadas antes $\mathrm{y}$, de alguna manera, sigue hasta la fecha, porque, pese al desarrollo acelerado de las telecomunicaciones, de la tecnología y de internet, así como de los estudios cuantitativos y de las técnicas para el procesamiento de 
grandes bases de datos y documentos, no hubo novedades tan revolucionarias o cambios demasiado radicales que hayan determinado el inicio de un nuevo periodo en las prácticas historiográficas. Una nueva configuración se dio, en cambio, a finales del siglo XIX, con la emancipación definitiva de la historia de otras disciplinas como la filosofía y la literatura, de las corrientes románticas y, asimismo, de la religión, y su acercamiento a las ciencias naturales y a la academia gracias a la difusión de prácticas, instituciones, métodos, herramientas, modos de circulación y socialización de saberes y teorías.

Las rupturas y las crisis de civilización representadas por la primera y la segunda guerras mundiales y abiertas en los estudios históricos se van sanando con la expansión e internacionalización de las investigaciones en la segunda mitad del siglo pasado, en particular desde la década de 1970, pero con cierta continuidad estilística (uso de notas, modelo de la Cambridge Modern History, presencia de revistas especializadas, difusión en congresos y correspondencias, cada vez más "electrónicas", y en páginas web, entre otros elementos), que ha consolidado formas reconocidas, estandarizadas y aceptadas globalmente.

Por otro lado, sí hubo también discontinuidades importantes: el aumento de los historiadores profesionales a lo largo del siglo; la universalización del modelo del "estudioso" centroeuropeo o renano de finales del siglo XIX, aunque los enfoques y centros de atención se han ido intercambiando y modificando; la multiplicación de las revistas académicas, de 150 en 1900 a más de 5000 hoy en día; el crecimiento del público de lectores de la historia, pero en forma de nicho de mercado, de especialistas; la historia como producto del trabajo de profesores e investigadores universitarios y ya no sólo de "vanguardias de sabios" o de eruditos forjadores de la "historia patria", política, elitista y nacional. Sin embargo, las diferencias más profundas, más allá de estos factores y de la continuidad de ciertas modalidades y estilos, se manifiestan en la calidad del trabajo realizado, en sus temáticas y resultados.

Si bien hay obras que marcaron la pauta de la segunda parte del siglo, como por ejemplo La Méditerranée et le monde méditerranéen à l'époque de Philippe II de Fernand Braudel (1949), para la cual el autor revisó archivos a lo largo de todo el Mediterráneo e introdujo en el análisis distintas temporalidades y ritmos, según un enfoque distinto de lo que se consideraba "la tradición", es más complicado debatir el conjunto historiográfico del siglo, mucho más fragmentado y desanclado de corrientes ideológicas y de pensamiento "abarcadoras", del positivismo al nacionalismo, del marxismo y del estructuralismo al romanticismo. 
Hasta la década de 1930, se da por sentado que se construye la historia desde un centro que excluye la periferia, pues los estados nacionales como objeto de investigación-creación prevalecen sobre lo regional y local, Occidente sobresale con respecto de otras civilizaciones y finalmente Europa, y luego los Estados Unidos, tienen un lugar privilegiado frente a las colonias, donde están las no-civilizaciones, los espacios sin historia, sin códigos escritos, lugares que simple e ideológicamente tienen menos importancia para la historia universal. Lo mismo ocurre dentro de cada país o nación, pues todavía a finales del siglo XIX destacan las historias políticas, militares y diplomáticas formuladas en los centros: Alemania hasta los años 1910, Francia hasta los años 1960 y, después, el mundo anglosajón, Estados Unidos e Inglaterra.

Entre las dos guerras mundiales, las pretensiones de cientificidad del método alemán son atacadas, por un lado, por el historicismo de Benedetto Croce, quien, mediante su revista La crítica, no apoya la progresiva retirada del método histórico de los problemas planteados por la literatura y la filosofía, y por otro lado por quienes ya no ven en la historia de individuos y naciones el soporte de la investigación, al hacer hincapié en la historia económica y social, en los sujetos colectivos y en las distintas "periferias" de antaño (Bloch, 1952; Braudel, 1986a). Las interpretaciones marxistas, el materialismo histórico y el pensamiento socialista aplicados a la historiografía y a las ciencias sociales van nutriéndose a lo largo del siglo de las aportaciones europeas y latinoamericanas, conquistan espacios importantes en las universidades a partir de los años 1960 y determinan el debate en los partidos políticos y en los movimientos populares y revolucionarios, desde los años 1920 hasta la era de la Guerra fría y el fin del siglo XX (Croce, 1961; Mariátegui 2007; Bagú, 1992; Hobsbawm, 2002; Gunder Frank, 1967).

La Histoire économique et sociale de la France, coordinada por Braudel y Labrousse (1982), y, antes, la revista de los Annales d'histoire économique et sociale, fundada en 1929 y dirigida por Marc Bloch y Lucien Febvre (Bairoch, 1997), autores de la primera generación de la Escuela de los Annales, hacen hincapié en las vetas de la historia monetaria y de los precios, rural y demográfica, de la colonización y la expansión del capitalismo, de las industrias y la agricultura, de los oficios, las técnicas y la construcción, de las familias y de las crisis económicas, ampliando enormemente el campo de actividades humanas y culturales sujetas al análisis histórico. No se trata, en realidad, de una verdadera "escuela", aunque internacionalmente se difundió esta definición, sino que los mismos integrantes de esta corriente subrayaban, más bien, sus diferentes enfoques individuales dentro de un marco común, como lo ha señalado 
Aguirre Rojas (2005). Esta nueva generación de historiadores mantenía una posición crítica respecto del enfoque de las historias nacionales, del cual fueron un ejemplo destacado los 27 tomos publicados entre $1910 \mathrm{y}$ 1922 por Ernest Lavisse, titulados Histoire de France depuis les origins jusqu'à la Révolution (Historia de Francia desde los orígenes hasta la Revolución), en su calidad de forjadoras de identidades nacionales, porque pudieron contar entre los factores que exacerbaron los nacionalismos que finalmente condujeron a la Primera Guerra Mundial (Allier Montaño, 2008, p. 168).

"La llamada historia económica, que se encuentra todavía en proceso de construcción, [...] no es la historia noble [..., pero no deja por ello de plantear todos los problemas inherentes a nuestro oficio: es la historia integral de los hombres, contemplada desde cierto punto de vista", escribió Fernand Braudel en su ensayo "La dinámica del capitalismo" (1986b). La periferia, entonces, cambia, al marginarse la historia político-militar, la del derecho y las instituciones y de los "grandes personajes". Asimismo, la centralidad total de Occidente, en especial de Europa, y la historia entendida como "dominio de una serie de hechos" se tornan periféricas, aún más después de la descolonización en los treinta años que siguen al segundo conflicto mundial (Said, 2013).

No obstante, la más reciente desaparición de centros absolutos de alguna manera ha redimensionado el mismo concepto de lo que sería "periferia" con respecto del mainstream en el hacer historiográfico. Más allá del mapa trazado por los grandes cambios y las largas duraciones, por las estructuras y las coyunturas, las temáticas y las fuentes se han multiplicado, generando un sinnúmero de clasificaciones y posibilidades, junto a contaminaciones con otros lenguajes y disciplinas como la etnografía, la economía, la administración, la psicología, la arqueología, la antropología y la sociología, para citar algunos ejemplos.

Duraciones y ritmos, a partir de la obra de Braudel y de su reflexión sobre historia y ciencias sociales (1986a), han caracterizado el quehacer histórico del siglo Xx, pues se han tornado elementos tratables, analizables, del tiempo histórico que, a diferencia del siglo anterior, no se considera ya como un bloque homogéneo o unitario. Por consiguiente, se separan en categorías distintos acontecimientos, coyunturas y estructuras como elementos para explicar la realidad histórica, según diferentes duraciones o tiempos que no son los mismos: los procesos de cambio en el poder político o una lucha independentista siguen ritmos distintos de los que caracterizan los ciclos económicos o las innovaciones tecnológicas, los cambios culturales o el desarrollo y expansión de un modo de producción, pues se puede pasar del dominio de lo estructural y de la larga duración 
a las coyunturas y, finalmente, a los acontecimientos que en ese contexto se enmarcan (Cibotti, 2003).

En las últimas cuatro décadas del siglo, conforme se generalizaban ciertos avances tecnológicos y enfoques metodológicos, las corrientes de la historia económica, como por ejemplo la Historia Cuantitativa, la Nueva Historia Económica (New Economic History) o la Historia Serial, se orientaron cada vez más al uso de fuentes cuantitativas y hasta de modelos econométricos cada vez más complejos, que podían sintetizar los problemas en fórmulas matemáticas y dar cuenta de fenómenos como la división internacional del trabajo (Furtado, 1968), el proceso de desarrollo o las desigualdades (Rostow, 1968) y ciclos de producción en el sistema capitalista (Kuznets, 1967; Fontana, 1982, pp. 167-213).

La revista de los Annales, fundada en 1929 con el nombre de Annales d'histoire économique et sociale, va reflejando los cambios en sus enfoques o líneas epistemológicas en sus cambios de nombre: después de la Segunda Guerra Mundial, en 1946, se llama Annales. Économies, sociétés, civilisations (Anales. Economías, sociedades, civilizaciones), lo cual evidencia un interés mayor en una dimensión planetaria, serial y cuantitativa, los ciclos económicos y una mayor pluralidad de sociedades y civilizaciones abordadas, y en 1994 el título pasa a ser Annales. Histoire, Sciences Sociales (Anales. Historia, Ciencias Sociales) y subraya la creciente integración, que ya estaba en marcha desde por lo menos hacía un par de décadas, con las ciencias sociales, y una mayor atención al presente, a "las historias" en plural, a la oralidad, a la memoria y al acercamiento con el gran público (Allier Montaño, 2008, pp. 171-172).

Además del afianzamiento de las pesquisas económico-sociales, como escribió Arnaldo Momigliano (1984), en la década de 1980 creció el interés por los sectores subalternos, los oprimidos de las sociedades industriales y su historia cultural, ya que ésta se empieza a ocupar de las mujeres, los esclavos, las minorías, los niños, los obreros, los campesinos, los herejes u otras categorías. Junto a este movimiento, se popularizan otros temas ligados con la economía, la antropología y la sociología, aunque no sólo, que van de la historia urbana a la de las religiones, de las relaciones entre sexos a la lectura, del revisionismo sobre totalitarismos e imperios a la dimensión social de la política.

Las visiones estructuralistas y "seriales" no han impedido otros desarrollos, entre los cuales destaca la obra de Michel Foucault sobre la locura (2006), la clínica (2007), la cárcel, el sistema penal (2015) y la sociedad punitiva (2016) y la sexualidad (2005a; 2005b), dentro de su formulación de la historia de los sistemas de pensamiento en Occidente que, sin duda, ha contribuido de manera importante a la superación de la dicotomía en- 
tre las esferas de lo cultural y lo social y a la construcción de una historia sociocultural. La historia social llega a estudiar las redes y los nexos de parentesco o de favores clientelares, la económica analiza los patrones de consumo y de producción o se mueve hacia la arqueología industrial y la business history, la cultural y la artística hacen historia, por ejemplo, sobre la alimentación y los medios visuales o prosopografía, es decir, biografías públicas de personas, entendidas como partes de un colectivo social (Hudson, 1983; Amatori \& Colli, 2011).

En la década de 1970, a partir del linguistic turn o giro lingüístico, expresión acuñada por el filósofo austriaco Gustav Bergmann en 1964 y popularizada por el filósofo estadounidense Richard Rorty, quien tituló una colección de ensayos The Linguistic Turn, Essays in Philosophical Method (Rorty, 1967), se consolida el maridaje entre la historia, las técnicas narrativas y literarias y la lingüística, el cual acaba teniendo repercusiones en todas las ciencias sociales y se manifiesta en la tendencia a sustituir el lenguaje académico formal y esquemático característico del marxismo, del estructuralismo y de los enfoques cuantitativos, con un lenguaje más comprensible construido mediante relatos, con un estilo más elegante y estructuras narrativas coherentes; sin embargo, esto no implica renunciar al rigor científico. Como muestran, por ejemplo, las obras emblemáticas asociadas con la nueva historia narrativa del historiador del arte inglés Simon Shama (1999) y de la estadounidense Natalie Z. Davis (1983), se da a finales del siglo Xx la incorporación de nuevos temas, pero sobre todo de nuevas metodologías y epistemologías que profundizan la distancia respecto de las corrientes historiográficas más importantes que veían con menosprecio la función narrativa del historiador frente a la más esencial tarea interpretativa: la de los Annales en Francia, la de los marxistas británicos y la de la cliometría estadounidense (Aurell, 2004, p. 10).

Las corrientes postmodernas, incluyendo el giro lingüístico, sobre todo a partir de la década de 1980, van proponiendo una forma de vuelta hacia el sujeto, el individuo, y hacia la narración, lo cual desde la perspectiva de los primeros Annales se concebiría como un retorno a la histoire événementielle y a una suerte de status quo ante respecto del paradigma rankeano, que justamente había pretendido superar la fase narrativa de la historia. Por otro lado, tienden a suplantar mediante el relativismo y la fragmentación los grandes esquemas teóricos y estadísticos dominantes antes de los años setenta y ochenta del siglo Xx, basados en el marxismo, en el idealismo de cuño liberal o inclusive en la historia cuantitativa (también llamada "cliométrica") y ponen en tela de juicio la distinción entre lo real y lo imaginario, ensalzando las representaciones y la memoria de las cosas (Stone, 1979). 


\section{Del siglo xx al xxI: vieja y nueva historia,}

giro cultural, historia oral, historia global

La óptica comparativa, asimismo, caracterizaba la escuela de los Annales, que ya en 1928 con Marc Bloch y Lucien Febvre proponía estudiar las sociedades europeas, ya no las naciones o los países, sus distintas estructuras económico-sociales internas, sus ciclos y la economía-mundo. El núcleo ya no residía en el carácter individual e irrepetible de todo fenómeno histórico, sino en las estructuras subyacentes y en la larga duración que, de alguna manera, llegan a determinar, mejor dicho "a enmarcar", el desarrollo de los acontecimientos.

Las contraposiciones ideológicas entre bloques durante la Guerra Fría y la aparente contraposición entre dos tipos de sociedad, la capitalista y la colectivista, que instauró otro tipo de capitalismo llamado "de Estado", polarizaron la historiografía; pero tal polarización se quebró tras la caída del Muro de Berlín y con la pretensión de que la historia pudiera tener "un fin" en el sentido que le dio Fukuyama (1994) de fin de las ideologías, triunfo definitivo de las democracias liberales y fin de las guerras y las revoluciones sangrientas. Pese a sus planteamientos, las perspectivas eurocéntricas o centradas en Occidente estaban siendo enfrentadas por las reivindicaciones de otras escuelas historiográficas. Ya en los años 1950 Joseph Needham había trabajado los aportes de China al desarrollo científico y comercial internacional, y en 1979 y 1987, respectivamente, se publicaron Orientalismo de Edward Said y Atenea Negra del inglés Martin Bernal, que provocaron olas de debates y polémicas e inauguraron líneas que pretendían superar las contraposiciones entre historiografías "marxistas" y "burguesas".

Durante el Congreso Internacional de Ciencias Históricas en Oslo en el año 2000, setenta y dos años después de que Marc Bloch abogara por una historia comparada de las sociedades europeas, se registró el surgimiento del enfoque de la "historia global" que, aunque estaba aún en pañales, según los organizadores, había tenido un largo periodo de incubación, pues se remontaba al trabajo de 1963 del historiador estadounidense William McNeill titulado The Rise of the West, el cual consideraba los efectos de las diferentes civilizaciones mundiales sobre las demás y veía la historia como relación entre sociedades con civilizaciones diferentes mas no aisladas o separadas, sino con sus encuentros y desencuentros.

El desarrollo europeo encaja, entonces, en un contexto más amplio, "euroasiático", en cuyo espacio se dieron innumerables intercambios, comercios y migraciones. De esta manera el horizonte se extiende geográfica y temporalmente de Europa a Asia y de la primera expansión imperial 
europea a una época anterior, la que André Gunder Frank (1998) llamó "edad asiática" y que se caracterizó por un floreciente intercambio entre la potencia China de las dinastías Ming (1368-1644) y Oing (1644-1911), Indonesia, la India, las costas de África y el mundo árabe.

Las influencias orientales sobre la civilización europea servían para romper el mito de la separación de los continentes junto al énfasis en las relaciones marítimas. Otro aspecto que de alguna manera profundiza la idea de longue durée braudeliana es la extensión que hace la Global History del alcance temporal de la historiografía, aunado a las nuevas relaciones con algunas ciencias como la biología, la geografía y la genética: se trata de vínculos que parecían improbables hasta hace algunas décadas y que marcan la labor del historiador a la fecha, junto con el interés por "los tiempos antes de la historia", antes de la escritura, y la toma de conciencia de que el pasado histórico sólo es una fase relativamente reciente en la historia de la humanidad, así como la centralidad europea es tan sólo un momento de la historia universal.

Al respecto, Hartog (2017, pp. 30-31) habla de un "giro global" de la historia y de un nuevo régimen de temporalidad que se puede definir como "presentista", el cual se funda en el instante, en la simultaneidad, en la inmediatez digital y en la ilusión de que todo es contemporáneo de todo y "no hay más que presente", y se distingue del régimen antiguo de "historicidad" y del "moderno", que miraban respectivamente hacia el lado del pasado y del futuro para significar la experiencia histórica. El "régimen de historicidad presentista" indica el surgimiento de distintas concepciones sociales del tiempo y de la relación con él, para las cuales el año de 1989, con la caída del muro de Berlín y el fin de la Guerra Fría, de las grandes narraciones ligadas a ella y del horizonte socialista, por lo menos en su vertiente soviética, marca un parteaguas en el declive del régimen moderno de historicidad (Allier Montaño, 2008, p. 182). Este nuevo régimen y la visión de la historia presentista también se reflejaron en la disciplina histórica, pues en 1978 nació en París el Instituto de Historia del Tiempo Presente, por iniciativa de François Bédarida, con base en la idea de que "el deber del historiador es no dejar esa interpretación del mundo contemporáneo a otros, bien sean los media o los periodistas (por no hablar de los propagandistas), o bien las otras diversas ciencias sociales" (Bédarida, 1998, p. 23). Se señalan como elementos distintivos de los historiadores del tiempo presente el uso de fuentes diferentes, particularmente las orales; el esfuerzo por reintroducir la larga duración en el tiempo presente y por develar las relaciones entre rupturas y continuidades, y el enfoque comparativo y multidisciplinario en diálogo constante con las otras ciencias sociales (Bédarida, 1998). Se trata, de hecho, 
de una historia que "pone énfasis en los actores y las representaciones: no pretende conocer la 'realidad' de los sucesos pasados (pues no le interesa el 'acontecimiento' en sí), sino las que han sido y son las creencias y representaciones de ese pasado" (Allier Montaño, 2008, p. 185). La historia del tiempo presente tiene varias problemáticas que, en realidad, tampoco están ausentes de otros enfoques y maneras de hacer historia, pero son focos de atención especial que hay que tener en cuenta y señalar: establecer la "justa distancia" de los acontecimientos estudiados; la carencia de fuentes, en caso de que los archivos no hayan sido abiertos todavía, pero también la abundancia de otras fuentes como las orales o hemerográficas; el desconocimiento del "final de la historia", o sea de lo que pasó después, y la independencia científica del historiador (Bédarida, 1998, p. 24).

En el último cuarto del siglo pasado y en el principio de éste, el campo de estudio de la historia se ha expandido significativamente: de la historia mundial a la local, de la social a la económica, de la cultural a la oral, la urbana o la rural, para mencionar algunos ejemplos. La misma historia económica se ha dividido en "nueva" y "antigua". Hubo un vuelco del interés desde la producción al consumo y se dio un proceso de "invasión" o de superposición con el objeto de la historia social y de la cultural. También nacieron la historia de empresa o business history, a veces por demanda de las mismas compañías, la historia de la publicidad y la arqueología industrial. En el mismo sentido van las diferenciaciones dentro de la historia política entre la "alta" y la "baja", de los centros de poder al hombre de la calle, y la propagación de nuevos enfoques, problemas y objetos para una "nueva historia", total y estructural, según la propuesta de Jacques Le Goff (Le Goff, 1978; Le Goff y Nora, 1985) y la evolución de los Annales en su tercer periodo o generación. Peter Burke clasifica en siete puntos las principales diferencias entre historia vieja y nueva. Sintetizándolos, resumo los elementos de oposición entre ambas (Burke, 1993b, pp. 14-19).

Para el paradigma tradicional, el objeto de la historia es la política, básicamente el Estado nacional o la política internacional, no tanto el ámbito local; o bien las grandes instituciones como la Iglesia y los ejércitos. La historia se entiende como narración de acontecimientos vistos desde arriba, fundados en grandes hazañas de personajes de poder, y finalmente analizados por medio de documentos oficiales, sobre todo de gobiernos e instituciones, que el historiador recolecta en los archivos. También se da la mayor importancia a los sujetos o individuos de la historia, en sus pensamientos y acciones como modelos explicativos (Collingwood, 1946). No obstante, según la "vieja historia", el profesional ofrece a los lectores los 
hechos de manera objetiva, como si pudiera aislarse de su tiempo y cultura y proponer lecturas jamás ideológicas, con pretensiones de neutralidad. En el siglo XIX se dio la definitiva profesionalización de la historia y el afianzamiento de departamentos universitarios, publicaciones y congresos.

Según la nueva historia, a partir de la experiencia de los Annales de la década de 1930 en adelante, el interés del historiador puede dirigirse hacia casi cualquier actividad humana, pues "todo tiene una historia" y ésta tiende a ser "total", al incluir en su campo de estudio muchas materias que antes se consideraban inmutables y que, ahora, adquieren una historia propia y se interpretan, siguiendo las pautas de la antropología cultural, de manera relativa y como construcciones culturales. Periferia y centro de la historia llegan a confundirse y cambiarse de lugar. Lo que importa más son los cambios económicos y sociales de larga duración, de tipo estructural (Braudel, 1949), pero también, como reacción al "exceso de estructuralismo" y totalidad, aumenta el interés hacia la historia desde abajo (Sharpe, 1993), cuyos protagonistas son sujetos que antes no eran considerados: la gente de la calle, o los fieles comunes y corrientes y el bajo clero (Hoornaert, 1977), los portadores de la cultura popular o los profesionales, enmarcados dentro de cambios sociales más abarcadores y largos.

Los "terceros Annales" (1969-1989) impulsaron especialmente la llamada "historia de las mentalidades", basada en el estudio de las formas de la conciencia social de grupos, regiones, épocas o coyunturas específicas, una suerte de "antropología histórica" de los hábitos mentales y de la conciencia de los humanos que pudiera abarcar temas como la familia, la muerte, la religión, el miedo, la vida privada, la mentalidad o la concepción del trabajo, entre otros (Aguirre Rojas, 1998, p. 12).

En esta dirección, el acercamiento a casos individuales e historias de vida según la idea del "microscopio social" (Burke, 1993a, pp. 38-43), por el cual la selección de casos es significativa para el conocimiento de los mecanismos sociales, y una contaminación positiva con los métodos de la antropología (etnografía, entrevista, observación; Restrepo, 2016) también aparecen como parte de las nuevas tendencias historiográficas. La creatividad y la capacidad de cambio de los actores emerge, más allá de su mero papel responsivo frente al contexto que sugería el funcionalismo y del determinismo fijado desde las estructuras como postulaba el marxismo, en las discrepancias y los indicios que marcan desviaciones de la norma y particularidades no detectadas. Se trata, entonces, de rescatar aspectos de la historia que pueden darnos claves de lectura distintas de la realidad que en general son ignoradas por los métodos que bajan a lo "pequeño" en función de o a partir de lo "macro-grande" y lo "serial", 
como para encontrar una simple secuencia de ejemplos o una muestra representativa para confirmar hipótesis.

Entonces se da, en el marco de la fragmentación de enfoques, a partir de la tercera generación de los Annales, un movimiento hacia una historia interpretativa, plural y centrada en lo simbólico. El sueño de la historia total se dispersa, o bien se prefigura eventualmente como construible desde abajo hacia arriba (Revel, 1995, p. 497). En las últimas dos décadas del siglo pasado y en éste, las prácticas y los aspectos culturales, los imaginarios, los símbolos, los significados y las representaciones se tornan cada vez más centrales, así como el regreso al sujeto, a la singularidad, a la narración y a la interpretación, y la historia social experimenta un "giro cultural" (cultural turn) como "una crítica a la naturalización del mundo social plasmada en las historias socioeconómicas y demográficas", que cuestiona la "objetividad" de la escuela braudeliana y se centra más en los motivos que orientan las estrategias individuales y colectivas y en la comprensión "desde dentro" de las sociedades estudiadas (Moreyra, 2007, p. 14). A través de nuevas temáticas y perspectivas de análisis, la historia sociocultural se acerca al estudio de la cultura popular y a la antropología, renunciando a las pretensiones abarcadoras y el estudio de las grandes tendencias de la sociología, de la economía, de la historia económica y social, y se compone, por lo menos, de cuatro tendencias: la historia de lo cotidiano, la microhistoria, la historia de las mentalidades y la historia desde abajo, cuyo interés principal común "se sitúa en la interpretación de la realidad construida por los sujetos a través de sus prácticas, discursos y representaciones y cómo dan sentido a la realidad social" (Martínez Martín, 2007, p. 238).

La "historia de lo cotidiano" o "de la vida cotidiana" (Alltagsgeschichte), cuyo lema fue acuñado en Alemania a partir especialmente del trabajo de Alf Lüdtke (Lüdtke, 1995), se interesa en los mundos de la vida individual y cotidiana, en los sentimientos y en las vivencias de las personas, e interroga a los hombres y a las mujeres comunes y corrientes con el fin de comprender cómo han sido vividos los grandes procesos históricos y las estructuras. Burke (1993c, p. 106) incluye en esta denominación también la historia de las prácticas sociales y culturales que Bourdieu (1972) llama "teoría de la práctica" y Stephen Greenblatt (1988) "la poética de la cultura".

A partir de perspectivas similares, en Italia a mediados de la década de 1970 surge la microhistoria, centrada en el estudio del pasado desde los pequeños grupos sociales de la comunidad, la familia, el barrio o la aldea. Este enfoque arranca del trabajo pionero de Carlo Ginzburg (1976), que cuida particularmente el aspecto narrativo y el análisis denso de un 
caso particular por sobre del análisis de tendencias estructurales y de largas duraciones (Martínez Martín, 2007, p. 246). Parafraseando al historiador italiano Edoardo Grendi (1972), lo anterior puede ayudar a formular la representación de ese "excepcional normal" que la microhistoria utiliza, a partir de las anomalías más que de las series de datos y de las homogeneidades comparables, para evidenciar

las incoherencias de la realidad y de los sistemas normativos, en cuyo interior se construyen las rutas estratégicas de los actores históricos [...] Excepcional normal, entonces, porque un testimonio, un documento, un acontecimiento únicos contienen en sí elementos tan normales que no habían sido vislumbrados anteriormente (Fazio, 2000).

Estos desarrollos representaban una reacción desde la "periferia" del medio científico internacional especializado, siendo Francia el referente "central" del paradigma historiográfico después de los primeros Annales (Revel, 1994, p. 551). Según Castelnuovo y Ginzburg (1979), la periferia no sería el espacio del retraso y de la imitación de los grandes centros artísticos, sino que, en ciertas fases, se convierte en el lugar para la generación de alternativas desenlazadas de los cánones en boga y de alguna manera contrahegemónicas, y este razonamiento puede aplicarse a la historiografía francesa y a sus "periferias".

La "historia de las mentalidades", que nace y se desarrolla en Francia, encuentra su definición más acabada en la obra monumental en siete volúmenes, aparecidos entre 1984 y 1992, de Pierre Nora, Los lugares de la memoria, la cual se centra en la definición del mismo concepto de "lugar de la memoria" como sitio en que "se ancla, condensa, cristaliza, refugia y expresa la memoria colectiva" (Nora, 1992, p. 20). El enfoque se ha visto como una respuesta frente a la forma casi deshumanizada que había tomado una parte de la historia económica a finales del siglo pasado, y se ha nutrido de los recursos de la etnografía y de la antropología para acercarse a la realidad, prestando particular atención a los grupos considerados marginales y excluidos de la pretendida universalidad de la Modernidad (Silva Riquer, 2015, p. 29). Por lo tanto, progresivamente la historiografía francesa va alejándose del estudio de las variables seriales y de la historia económica y social anterior, que aún influían en parte de la historia cultural o "de las mentalidades" de este país en las décadas de 1960 y 1970, mientras se acerca al individuo, al unicum de las prácticas y vivencias culturales, y se redefine como "historia de las representaciones" (Chartier, 1988), pues las personas y los colectivos atribuyen sentidos a su mundo por medio de las representaciones y también de las 
operaciones o de las prácticas sociales que filtran a la sociedad a través de la cultura (Martínez Martín, 2007, p. 251).

La "historia desde abajo" inglesa se define así, "from below", tanto por su temática, que se enfoca en la historia de la gente común y del pueblo, como por su perspectiva, que construye una historia vista por esa misma gente común que incluye grupos marginados y tradicionalmente silenciados en la investigación de una "historia de la cultura popular", no sólo en Europa sino en otras partes del mundo (Burke, 1993c, p. 106). Un ejemplo destacado es el grupo de autores de los llamados "estudios subalternos" (o poscoloniales) en la India, guiados por Ranahit Guha (2002), quienes arrancan desde una crítica del saber centrado en Occidente. Por ejemplo, cuestionan la categoría de "pre-político", acuñada en la década de 1950 por Eric Hobsbawn, al escribir sobre los "rebeldes primitivos" (2001) desde la perspectiva del marxismo británico, y conciben la subalternidad no tanto en los términos de la clase social de cuño marxista, de lo contrahegemónico o de lo "incompleto" que prefigura algo superior, sino dentro de la dialéctica entre lo colonial y lo postcolonial aplicada a los estados nacionales (Archila Neira, 2005, p. 296). Se trata, entonces, de sacar al subalterno de las visiones eurocéntricas que, incluso desde posiciones marxistas que teóricamente serían empáticas con la subalternidad, tienden a silenciarlo reduciéndolo a abstracciones procedentes desde fuera, como "el proletario" o el "colonizado", o a transformarlo, a partir de corrientes posmodernas del giro lingüístico, de una condición social concreta a un producto del discurso (Guha, 2002, pp. 17-32).

$\mathrm{Al}$ proliferar los ámbitos de interés, aumentan también las fuentes y sus tipologías aceptables, desde las visuales y "artísticas" a las orales, de las estadísticas (centrales en los enfoques cuantitativos) a las arqueológicas y lingüísticas. El porqué de los acontecimientos se ha de buscar mucho más en tendencias y estructuras que en acciones y pensamientos individuales (Furtado, 1962; Florescano, 1979). Si por un lado la cliométrica ha expandido su ámbito de aplicación de la historia de la economía y de la demografía a varios otros tipos de historia en los años 1950 y 1960, igualmente la historia serial, fundada en datos ordenados en series cronológicas, se ha utilizado en la historia económica, de los precios y de la población, pero también el llamado "tercer nivel" de la historia ligado al estudio de las mentalidades (Appadurai, 1986; Aydelotte, 1971; Chaunu, 1978). Además, el relativismo cultural y la conciencia de ello fueron permeando la investigación y sus objetos, y así la idea de la Voz (única) de la Historia dejó su lugar a la heteroglosia, a un conjunto de voces diversas y opuestas que hay que contrastar y comparar, manteniendo asimismo una mirada interdisciplinaria e integrándolas (Certeau, 1986). 
La historia oral, es decir "la especialidad dentro de la ciencia histórica que utiliza como fuente principal para la reconstrucción del pasado los testimonios orales" (Mariezkurrena Iturmendi, 2008, p. 227), constituye un ejemplo significativo de un enfoque metodológico que ha ido ganando más legitimidad, a la luz de la difusión de la historia social y, sobre todo, del "giro cultural" de finales del siglo xx y principios del XXI, y que es cada vez más utilizado para la investigación cualitativa en historia como en sociología, antropología, psicología, economía y demás ciencias sociales. En parte, el creciente interés por la historia oral se debe a la difusión de la historia del tiempo presente (o historia "inmediata"), ya que ésta hace hincapié en la opción de entrevistar a los testigos y, aunque las fuentes orales así generadas no representan el fiel reflejo del pasado sino el recuerdo de lo vivido, su fuerza estriba en la posibilidad de "trabajar con la memoria", de explorar la relación entre memoria individual y colectiva y cotejar relatos, vivencias y percepciones del pasado, permitiendo, finalmente, "el estudio de la relación entre historia y memoria" (Sauvage, 1998, p. 17).

La historia oral había sido considerada por la historiografía tradicional poco adecuada para plantear hipótesis, marginal para la Historia con h mayúscula, pues según el paradigma tradicional no había historia sin documentos. "Cuando no existe la escritura, o prácticamente no se halla presente, las tradiciones orales han de llevar el peso de la reconstrucción histórica. Pero no lo harán de la misma forma que las fuentes escritas", expresó el oralista y africanista Jan Vansina, quien destacó, igualmente, que "la reconstrucción a partir de las fuentes orales puede muy bien poseer un grado bajo de fiabilidad si no se cuenta con fuentes independientes para contrastar" (Vansina, 1985, p. 199). De esta manera, son numerosas las líneas de investigación que se han visto beneficiadas en la última parte del siglo pasado y al principio del actual por la difusión de la historia oral como herramienta para la historia económica y social (Iglesias, 1984, pp. 59-70).

Paul Thompson, uno de los portavoces del "movimiento" de la historia oral en la segunda mitad del siglo xx, defendió el valor de las fuentes orales en la historia social moderna, ya que "la oposición a la evidencia oral se basa tanto en consideraciones personales como en principios" y se establece en la vieja generación de profesores que "ya no controlan todas las técnicas de su profesión" y son "reacios a la introducción de nuevos métodos" (Thompson, 1988, pp. 83-84). Se da por sentado entonces que, cuando no haya otras opciones, se consideran las fuentes orales como predominantes, aunque ya no únicamente en esa situación, sino igualmente cuando se encuentren otras fuentes o documentos referidos 
a la historia del tiempo presente: las fuentes orales pueden apoyar el proceso de corrección, deconstrucción y reconstrucción de perspectivas, versiones e informaciones, a la par de las fuentes no orales que van a perfeccionar los hallazgos conseguidos mediante la oralidad. En este sentido, el enfoque metodológico de la historia oral y sus técnicas, como la entrevista en profundidad, han expandido su campo de aplicación en el marco de un creciente diálogo interdisciplinario, especialmente entre la teoría social y la historia, por lo que se ha creado una interacción fructuosa entre disciplinas y conceptos, no exentos todavía de embates entre visiones del mundo distintas, que ha involucrado cada vez más la sociología, la antropología, la psicología y la historia, entre otras (Burke, 1993a).

Los enfoques desprendidos del llamado "giro cultural", especialmente la historia desde abajo, la historia de las mentalidades, la microstoria y la historia de lo cotidiano, pero también la historia narrativa y la historia más etnográfica y antropológico-simbólica de Natalie Z. Davis y Robert Darnton en Estados Unidos, han sido objeto de distintas críticas. Muchos de estos historiadores han optado por incorporar la descripción de los procedimientos de investigación, incluyendo a menudo sus hipótesis, sus inquietudes y la justificación sobre las fuentes, en la misma narración histórica, a raíz de que la innovación en las fuentes utilizadas requería mayores explicaciones o justificaciones, pero esta práctica ha creado un sentido de familiaridad y cercanía con el público lector que ha sido objeto de críticas (Port, 2015, pp. 110-111). Se ha señalado también el riesgo de un uso excesivo de las perspectivas y de las categorías del presente para tratar el pasado, así como de volver demasiado románticas o folclóricas las narraciones del pasado, sobre todo cuando se refieren a personajes del imaginario popular o a grupos sociales "en resistencia".

Una cuestión importante a considerar es la representatividad del caso estudiado, de la comunidad o del acontecimiento analizado, que, dada la escala muy pequeña adoptada sobre todo por la microhistoria, la historia de lo cotidiano y "desde abajo", presenta más problemas, pues si por un lado todo acontecimiento de por sí se puede considerar "único", por el otro la tendencia en el siglo xx (Carr, 1961) había sido crear concatenaciones, nexos causales, hipótesis y explicaciones más abarcadoras que pudieran dar cuenta de tendencias y estructuras, más allá de las puras narraciones. Si bien puede darse la posibilidad de que los casos sean comparables, como parte de una suerte de acervo, no siempre es así. Como respuesta se ha formulado la ya mencionada idea de "lo normal excepcional" de Grendi. Esto es forma de "comportamiento inusual que desafía las normas prevalecientes, que es la verdadera razón por la cual dejan rastro en los archivos" (Port, 2015, p. 112); pero, aun siendo 
considerados como desviaciones por las elites o por las instituciones, en realidad para la gente común se trata de comportamientos normales y, entonces, llegan a ser consideradas como "perfectamente representativos de su propio ambiente social" (Muir, 1991, p. 27) y, por tanto, útiles para la construcción historiográfica.

Con su "constante ida y vuelta entre una micro y una macrohistoria, entre primeros planos y panorámicas", según la descripción de Levi (1991, p. 27), el ejemplo de la obra en dos tomos de Marc Bloch (1939-1940) sobre la sociedad feudal parece representar un equilibrio emblemático entre distanciamiento e involucramiento. También un punto central es mantener el equilibrio entre el determinismo, la idea de fuerzas "ciegas" que dominan a las personas en la historia, y el libre albedrío o capacidad de decisión, de acción y de influencia de los actores considerados, un problema que, como lo otros que se mencionaron, atañe a todo historiador en realidad, pero que, en el caso de las corrientes consideradas, se detecta de modo más destacado y apremiante, ameritando una mayor discusión y consideración (Gregory, 1999, p. 105).

\section{A manera de conclusión}

No todos los planteamientos de la "nueva historia" se originaron en el siglo $\mathrm{xx}$, pues estaban ya presentes en diferentes autores y debates anteriores, aunque sí se sistematizaron plenamente en esa centuria las críticas de los viejos paradigmas y se hicieron planteamientos orgánicos y consecuentes. Entonces, la misma visión despectiva que describe la vieja historia como una práctica fundada en puros acontecimientos, una histoire événementielle contrapuesta a la historia total y estructural de los Annales, había sido acuñada una generación antes de que aparecieron los trabajos de Bloch, Febvre y Braudel, quienes, de todas formas, llevaron la delantera en la afirmación de un nuevo paradigma (Burke, 1990, p. 113).

Tras los giros lingüístico y cultural en la historiografía, la consolidación de la metodología de la historia oral y del enfoque de la historia global, se ha afianzado un diálogo creciente de la Historia y las demás ciencias sociales, pues éstos y otros enfoques, surgidos a finales del siglo pasado han perdurado evolucionado en lo que va de esta centuria y han podido establecer equilibrios y diálogos interdisciplinarios, pero incorporando también enseñanzas, conceptos y visiones de la historia heredados de las experiencias anteriores que, más que "estar acabadas", han confluido en las corrientes actuales y las han moldeado. En 1991, ante el asombro por la caída del muro de Berlín y el fin de la Gue- 
rra Fría, el historiador estadounidense Robert Darnton, quien durante mucho tiempo había defendido la crítica braudeliana contra la historia de acontecimientos o événementielle, escribía: "Antes fui de los que menospreciaban el acontecimiento. Pero cuando me he visto inmerso en una ola de acontecimientos revolucionarios, me he encontrado a mí mismo poniendo en cuestión mis antiguas certezas" (Darnton, 1991, p. 10). Por el otro lado, se ha observado una progresiva flexibilización de las posturas postmodernas y relativistas que, sin renunciar a una historia social centrada en el sujeto y cercana incluso a la antropología y a la etnografía, han comenzado a reincorporar la perspectiva de la larga duración, la estructura y el contexto dentro de sus marcos conceptuales y operativos.

Se ha mostrado cómo, en la segunda mitad del siglo xx, la ampliación de las fuentes y de las técnicas de recolección de información, incluyendo el caso descrito en este artículo de las fuentes orales, ha abierto las puertas a una historia más completa, especialmente en aquellos ámbitos culturales y geográficos lejos del contexto europeo o de los de larga tradición en el uso de la escritura, como son partes de África y Asia, y asimismo América Latina, que representan entornos relevantes en que se ha aplicado con éxito (Wesseling, 1993, pp. 89-119). Asimismo, los historiadores se han encargado cada vez más de responder a una serie de demandas sociales que provienen de una multiplicidad de actores, grupos e instituciones, ya no sólo académicas o gubernamentales, de las sociedades en que operan.

Si por un lado el surgimiento de nuevas subdisciplinas, enfoques y métodos en la historia aparece como un proceso inevitable, así como el diálogo entre distintas disciplinas y lenguajes, por otro lado la fragmentación o la extrema especialización, según las tendencias del postmodernismo, pueden llevar a mayores dificultades de comunicación entre los mismos historiadores y entre sus ámbitos académicos de referencia, entre una constante búsqueda de nuevos "centros" y legitimaciones y un relativismo exacerbado. Lo anterior, desde luego, plantea los retos de la reconciliación de enfoques e hibridaciones interdisciplinarias, de la recomposición de la historia y de sus distintas aristas, del mantenimiento de la justa distancia, sobre todo cuando se trabaja con la historia reciente, y finalmente está el desafío de la reconciliación del acontecimiento con la larga duración, de la cultura y el ámbito de lo individual con lo colectivo y lo estructural. En el debate sobre la historia oral, el uso de las fuentes vivas y de documentos generados a partir de una interacción entre "sujeto" y "objeto" de estudio ha sido uno de los temas más discutidos, en la pugna por ganar legitimidad y rigor dentro de las ciencias sociales. Y es 
que éste es un anhelo de reconocimiento común para diferentes especialidades, metodologías y orientaciones dentro de la historia, así como en las ciencias sociales en general, las cuales han multiplicado las maneras de construir el conocimiento en las últimas décadas y necesitan un diálogo crítico no sólo con los distintos paradigmas historiográficos, sino con otras disciplinas antes percibidas como lejanas.

\section{Bibliografía.}

Aguirre Rojas, C. (1998)

"La corriente de los Annales y su contribución al desarrollo de la historia económica en Francia". Aportes: Revista de la Facultad de Economía-BUAP (17), pp. 11-36. Obtenido de http://www.unsa.edu.ar/ histocat/haeconomica07/aguirrerojasprimparte.pdf

Aguirre Rojas, C. (2005)

La "escuela de los Annales". Ayer, hoy y mañana. México: Contrahistorias.

Allier Montaño, E. (2008)

"Les Lieux de mémoire: una propuesta historiográfica para el análisis de la memoria". Historia y Grafía (31), pp. 165-192.

Amatori, F. y A. Colli (2011)

Storia d'impresa. Complessità e comparazioni. Milán: Mondadori. Appadurai, A. (1986)

The Social Life of Things. Commodities in cultural perspective. Cambridge: Cambridge University Press.

Archila Neira, M. (2005)

"Voces subalternas e historia oral". Anuario colombiano de Historia Social y de la Cultura (32), pp. 293-308.

Audiger, F. (2001)

"Investigaciones en didáctica de la Historia, de la Geografía, de la Educación Cívica y la formación de docentes", en AA.VV., La formación docente en el profesorado de Historia. Rosario: Homo Sapiens, pp. 113-137.

Aurell, J. (2004)

"Los efectos del giro lingüístico en la historiografía reciente". Rilce.

Revista de Filología Hispánica (20.1), pp. 1-16.

Aydelotte, W. (1971)

Quantification in History. Reading: Addyson-Wesley. Bagú, S. (1992)

Economía de la sociedad colonial. Ensayo de historia comparada de América Latina. México: Consejo Nacional para la Cultura y las Artes, Grijalbo. 
Bairoch, P. (1997)

Victoires et déboires: histoire économique et sociale du monde du XVIe siècle à nos jours. París: Folio Gallimard.

Bédarida, F. (1998)

"Definición, método y práctica de la Historia del Tiempo Presente". Cuadernos de historia contemporánea, pp. 19-27.

Bloch, M. (1952)

Introducción a la historia. México: Fondo de Cultura Económica.

Bordieu, P. (1972)

Esquisse pour une théorie de la pratique. París: Librairie Droz.

Braudel, F. (1949)

El Mediterráneo y el mundo mediterráneo en la época de Felipe II. México: Fondo de Cultura Económica.

Braudel, F. (1986a)

La historia y las ciencias sociales. Madrid: Alianza.

Braudel, F. (1986b)

La dinámica del capitalismo. México: Fondo de Cultura Económica.

Braudel, F., y E. Labrousse (1982)

Histoire économique et sociale de la France. París: Presses Universitaires de France.

Burke, P. (1990)

The French Historical Revolution. Cambridge: Stanford University Press.

Burke, P. (1993a)

History and Social Theory. Nueva York: Cornell University Press.

Burke, P. (1993b)

"Obertura: la nueva historia, su pasado y su futuro" en P. Burke, Formas de hacer historia. Madrid: Alianza, pp. 14-19.

Burke, P. (1993c)

"La Nueva Historia Socio-Cultural". Historia Social (17), pp. 105-114.

Carr, E. (1961)

¿Qué es la historia? Barcelona: Ariel.

Castelnuovo, E., y C. Ginzburg (1979)

"Centro e periferia" en G. Previtali, Storia dell'arte italiana (parte 1, vol. 1). Turín: Einaudi, pp. 285-351.

Certeau, M. de (1986)

Heterologies: Discourse on the Other. Minneapolis: University of Minnesota Press.

Chartier, R. (1988)

Cultural History between Practices and Representations. Ithaca: Cornell University Press. 
Chaunu, P. (1978)

Histoire quantitative, histoire sérielle (Cahiers des Annales, núm. 37). París: Colin.

Cibotti, E. (2003)

Una introducción a la enseñanza de la historia latinoamericana. Buenos Aires: Fondo de Cultura Económica.

Collingwood, R. (1946)

The Idea of History. Oxford: Oxford University Press.

Croce, B. (1952)

La historia como hazaña de la libertad. México: Fondo de Cultura Económica.

Darnton, R. (1991)

Berlin Journal 1989-1990. Nueva York: W. W. Norton.

Davis, N. Z. (1983)

The Return of Martin Guerre. Cambridge: Harvard University Press.

Elias, N. (1997)

Sobre el tiempo (2a ed.). México: Fondo de Cultura Económica.

Fazio, I. (2000)

Studi Culturali. Obtenido de Dizionario: http://www.studiculturali.it/ dizionario/lemmi/microstoria.html

Fevbre, L. (1975)

Combates por la historia ( $3^{a}$ ed. en español). Barcelona: Ariel.

Florescano, E. (1979)

Ensayos sobre el desarrollo económico de México y América Latina.

México: Fondo de Cultura Económica.

Florescano, E. (2012)

La función social de la historia. México: Fondo de Cultura Económica.

Fontana, J. (1982)

Historia. Análisis del pasado y proyecto social. Barcelona: Crítica, Grijalbo.

Foucault, M. (2005a)

Historia de la sexualidad. 2. El uso de los placeres. Madrid: Siglo XXI de España.

Foucault, M. (2005b)

Historia de la sexualidad. 3. El cuidado de sí. Madrid: Siglo XXI de España. Foucault, M. (2006)

Historia de la locura en la época clásica. Barcelona: Fondo de Cultura Económica.

Foucault, M. (2007)

El nacimiento de la clínica. Una arqueología de la mirada médica. Madrid: Siglo XXI de España. 
Foucault, M. (2015)

Théories et Institutions Pénales (Cours au Collège de France, 19711972). París: EHSS, Gallimard, Seuil.

Foucault, M. (2016)

La sociedad punitiva. Buenos Aires: Fondo de Cultura Económica.

Fukuyama, F. (1994)

El fin de la historia y el último hombre. México: Planeta.

Furtado, C. (1962)

Formación económica del Brasil. México: Fondo de Cultura Económica.

Furtado, C. (1968)

Teoría y política del desarrollo económico. México: Siglo XXI.

Ginzburg, C. (1976)

Il formaggio e i vermi. Milán: Einaudi.

Gooch, G. (1942)

Historia e historiadores del siglo XIX. México: Fondo de Cultura Económica.

Greenblatt, S. (1988)

Shakesperian Negotiations . Berkeley: University of California Press.

Gregory, B. (1999)

"Is small beautiful? microhistory and the history of everyday life". History and Theory, pp. 100-110.

Grendi, E. (1972)

"Microanálisis e historia social". Quaderni Storici (7), pp. 506-520.

Guha, R. (2002)

Las voces de la historia y otros estudios subalternos. Barcelona: Crítica.

Guizot, F. (1851)

Histoire de la civilisation en Europe. París: Didier et Cie.

Gunder Frank, A. (1967)

Capitalismo y subdesarrollo en América Latina. México: Siglo XXI.

Gunder Frank, A. (1998)

ReOrient: global economy in the Asian age. Oakland: University of California Press.

Hartog, F. (2017)

"Hacia una nueva condición histórica". Letras Históricas, PrimaveraVerano (16), pp. 19-34.

Hobsbawm, E. (2002)

Sobre la historia. Barcelona: Crítica, Grijalbo.

Hoornaert, E. (1977)

Historia da Igreja no Brasil: ensaio de interpretação a partir do povo. Petrópolis: Voces Paulinas. 
Hudson, K. (1983)

The Archeology of the Consumer Society. Londres: Heinemann.

Iglesias, E. (1984)

"Reflexoes sobre o quefazer da história oral no mundo rural". Dados

Revista de Ciencias Sociais, 1 (27), pp. 59-70.

Ingenieros, J. (1980)

"La evolución sociológica argentina", en J. Ingenieros, Ensayos escogidos. Buenos Aires: Centro Editor de América Latina.

Jean-Noël, L. (1981)

La enseñanza de la historia a través del medio. Bogotá: Cincel Kapeluz.

Kuznets, S. S. (1967)

Secular Moments of Production and Prices. Nueva York: A. M. Keller.

Le Goff, J. (1978)

La nouvelle histoire. París: Complexe.

Le Goff, J., y P. Nora (1985)

Hacer la historia. Barcelona: Laia.

Levi, G. (1991)

"On microhistory", en B. P., New Perspectives on Historical Writing.

Cambridge: Polity Press, pp. 93-113.

Lüdtke, A. (1995)

The History of Everyday Life. Reconstructing Historical Experiences and Ways of Life. Princeton: Princeton University Press.

Mariátegui, J.C. (2007)

Siete ensayos de interpretación de la realidad peruana. Caracas: Fundación Biblioteca Ayacucho. Obtenido de http://resistir.info/livros/mariategui_7_ensayos.pdf

Mariezkurrena Iturmendi, D. (2008)

"La historia oral como método de investigación histórica". Gerónimo de Uztariz (23-24), pp. 227-233.

Martínez Martín, J. (2007)

"El tiempo de la historia de la cultura". Historia Socio-Cultural (82), pp. 237-252.

McNeill, W. (1963)

The Rise of the West: A History of the Human Community. Chicago: University of Chicago Press.

Momigliano, A. (1984)

"La retorica della storia e la storia della retorica: sui tropi di Hayden

White", en A. Momigliano, Sui fondamenti della storia antica. Turín:

Einaudi, pp. 465-476. 
Moreyra, B. (2007)

La historia social más allá del giro cultural: algunas consideraciones. Santiago de Chile: Universidad Católica Silva Henríquez.

Mossner, E. C. (1980)

The Life of David Hume. Oxford: Clarendon Press.

Muir, E. (1991)

"Introduction: observing trifles", en E. Muir y G. Ruggiero, Microhistory and The Lost People of Europe (pp. vii-xxviii). Londres, Baltimore: The Johns Hopkins University Press.

Nora, P. (1992)

"Comment écrire l'histoire de France", en P. Nora, Les lieux de mémoire, t. 2, Les France. París: Gallimard, pp. 12-32.

Port, A. I. (2015)

"History from Below, the History of Everyday Life, and Microhistory" en A.V. y N. J. Baltes (ed.), International Encyclopedia of the Social and Behavioural Sciences, ${ }^{2}{ }^{\mathrm{a}}$ ed., vol. 11, Oxford: Elsevier, pp. 108-113.

Restrepo, E. (2016)

Etnografía: alcances, técnicas y éticas. Bogotá: Envión, Pontificia Universidad Javeriana.

Revel, J. (1994)

"Microanalisi e costruzione del sociale". Quaderni Storici, 29 (86 (2), pp. 549-575.

Revel, J. (1995)

"Microanalysis and the construction of the social", en J. Revel y L. Hunt, Histories: French Constructions of the Past. Nueva York: The New Press, pp. 492-502.

Rorty, R. (1967)

The Linguistic Turn, Essays in Philosophical Method. Chicago: University of Chicago Press.

Rostow, W. W. (1968)

Las etapas del crecimiento económico. México: Fondo de Cultura Económica.

Said, E. (2013)

Orientalismo. México: Debolsillo.

Sauvage, P. (julio-diciembre de 1998)

"Una historia del tiempo presente". Historia Crítica (17), pp. 59-70.

Shama, S. (1999)

Rembrandt's Eyes. Londres: Allen Lane, The Penguin Press.

Sharpe, J. (1993)

"Historia desde abajo", en P. Burke, Formas de hacer historia. Madrid:

Alianza Universidad, pp. 39-56. 
Sierra, J. (1985)

La evolución política del pueblo mexicano. Barcelona: Ayacucho.

Silva Riquer, J. (2015)

"Los métodos de la historia económica y sus perspectivas de estudio", en M. T. Cortés Zavala, Z. Pineda Soto, J. Silva Riquer y J. Uribe Salas, La historia, sus métodos y posibilidades de investigación. Morelia: Universidad Michoacana de San Nicolás de Hidalgo, pp. 15-45.

Stone, L. (1979)

"The Revival of Narrative: Reflections on a New Old History". Past and Present. A Journal of Historical Studies (85), pp. 74-94.

Thompson, P. (1988)

La voz del pasado. Historia oral (3ª ed.). Valencia: Alfons el magnanim. Vansina, J. (1985)

Oral Tradition as History. Madison: James Currey Publishers.

Weber, M. (1984)

La ética económica de las religiones universales-Ensayos sobre Sociología de la Religión. Madrid: Taurus.

Wesseling, H. (1993)

"Historia de ultramar", en P. Burke, Formas de hacer historia. Madrid: Alianza, pp. 89-118. 